A regenerative elastocaloric device: Experimental results

This content has been downloaded from IOPscience. Please scroll down to see the full text.

Download details:

IP Address: 130.226.56.2

This content was downloaded on 17/08/2017 at 08:15

Manuscript version: Accepted Manuscript

Engelbrecht et al

To cite this article before publication: Engelbrecht et al, 2017, J. Phys. D: Appl. Phys., at press: https://doi.org/10.1088/1361-6463/aa8656

This Accepted Manuscript is: (c) 2017 IOP Publishing Ltd

During the embargo period (the 12 month period from the publication of the Version of Record of this article), the Accepted Manuscript is fully protected by copyright and cannot be reused or reposted elsewhere.

As the Version of Record of this article is going to be / has been published on a subscription basis, this Accepted Manuscript is available for reuse under a CC BY-NC-ND 3.0 licence after the 12 month embargo period.

After the embargo period, everyone is permitted to copy and redistribute this article for non-commercial purposes only, provided that they adhere to all the terms of the licence https://creativecommons.org/licences/by-nc-nd/3.0

Although reasonable endeavours have been taken to obtain all necessary permissions from third parties to include their copyrighted content within this article, their full citation and copyright line may not be present in this Accepted Manuscript version. Before using any content from this article, please refer to the Version of Record on IOPscience once published for full citation and copyright details, as permission will likely be required. All third party content is fully copyright protected, unless specifically stated otherwise in the figure caption in the Version of Record.

When available, you can view the Version of Record for this article at:

http://iopscience.iop.org/article/10.1088/1361-6463/aa8656 


\title{
A regenerative elastocaloric device: Experimental results
}

Kurt Engelbrecht ${ }^{\mathrm{a}, *}$, Jaka Tušek ${ }^{\mathrm{b}}$, Dan Eriksen ${ }^{\mathrm{a}}$, Tian Lei ${ }^{\mathrm{a}}$, Chong-Yi Lee $^{\mathrm{c}, \mathrm{a}}$, Janez Tušek ${ }^{\mathrm{b}}$, Nini Pryds ${ }^{\mathrm{a}}$

${ }^{a}$ Department of Energy Conversion and Storage, Technical University of Denmark, Frederiksborgvej 399, DK-4000 Roskilde, Denmark

${ }^{b}$ Faculty of Mechanical Engineering, University of Ljubljana, Aškerčeva 6, 1000 Ljubljana, Slovenia

${ }^{c}$ Department of Energy and Environment, National Institute of Applied Sciences of Lyon, 69100 Villeurbanne, France

\begin{abstract}
Elastocaloric cooling and heating is an alternative cooling technology that has potential to be highly efficient and environmentally friendly. Experimental results are reported for two elastocaloric regenerators made of NiTi alloys in the form of parallel plates in two plate thicknesses. For the regenerator made of $0.2 \mathrm{~mm}$ plates, a maximum no-load temperature span of $17.6 \mathrm{~K}$ was achieved for an applied strain of $4.3 \%$. For the regenerator with $0.35 \mathrm{~mm}$ plates, a maximum temperature span of $19.9 \mathrm{~K}$ was reached for a strain of $3.5 \%$. The $0.2 \mathrm{~mm}$ regenerator failed after approximately 5200 cycles and the $0.35 \mathrm{~mm}$ regenerator failed after approximately 5500 cycles.
\end{abstract}

Keywords: Elastocaloric refrigeration, regenerator, superelastic,

\section{Introduction}

Elastocaloric heating and cooling is a potentially attractive technology for replacing vapor compression for room temperature cooling applications $[1,2,3]$. The têchnology is similar to magnetic refrigeration [4] in that it is based on a caloric effect in a solid refrigerant. The elastocaloric effect can be characterized as a change in temperature of a material when uniaxially strained. The strain causes the crystal structure to transform from

${ }^{*}$ Corresponding author: Kurt Engelbrecht Email address: kuen@dtu.dk (Kurt Engelbrecht) 
austenite to the lower energy martensite phase, which increases the material temperature when the process is performed adiabatically. When the strain of the material is coupled to a synchronized fluid flow, a regenerative cycle is realized. Elastocaloric cooling has been suggested as the most promising technology for energy savings in refrigeration and air-conditioning applications by a recent report [5] and increased research into its application for room temperature applications has also be suggested $[6,7]$. Although the technology has a large potential, devices operating under commercially relevant conditions have not yet been reported, and the technology remains relatively immature.

The elastocaloric effect is generally associated with superelasticity and the shape memory effect. Materials that exhibit a significant elastocaloric effect near room temperature include shape memory alloys, such as Ni-Tibased alloys [8, 9, 10,11], Cu-based alloys [12], and Fe-based alloys [13], shape memory polymers [14], including natural rubber $[15,16]$, and magnetic shape memory alloys [17]. Metallic elastocaloric materials are generally considered more attractive due to their higher densities, but natural rubber and shape memory polymers require lower forces to achieve high elastocaloric effects, which may make them more suitable for some applications. Multi-caloric systems potentially exhibit higher performance than pure elastocalorics, such as combining the electrocaloric effect with an applied strain [18], but no experimental applications of devices exploiting these effects have been reported to date. The system in this article uses Ni-Ti alloys as the refrigerant because they are commercially available and exhibit a high elastocaloric effect, with an adiabatic temperature change of $16 \mathrm{~K}$ or higher [19] and an isothermal entropy change upon strain of $30 \mathrm{~J} / \mathrm{g}[20,21]$. A major drawback of Ni-Ti is a relatively low fatigue life for operating conditions that are relevant to elastocaloric cooling [22]. Ref. [23] reported that polycrystalline samples of $\mathrm{Ni}-\mathrm{Ti}-\mathrm{Cu}-\mathrm{Co}$ have been shown to last over 10 million cycles, and the material has the potential to solve the problem of fatigue.

Although elastocaloric cooling is a relatively new research area, there are several devices reported. The elastocaloric effect can be triggered by either compression or tension, and devices operating on each principle have been reported. Devices based on straining a single plate in tension and using it to directly cool a load have been presented by $[24,25]$. A maximum temperature span of $7 \mathrm{~K}$ was reported for a Ni-Ti plate by [25] and a maximum temperature span of $9.4 \mathrm{~K}$ was reported by [26]. A system based on compression of $\mathrm{Ni}$-Ti tubes was reported by [2], with a maximum temperature

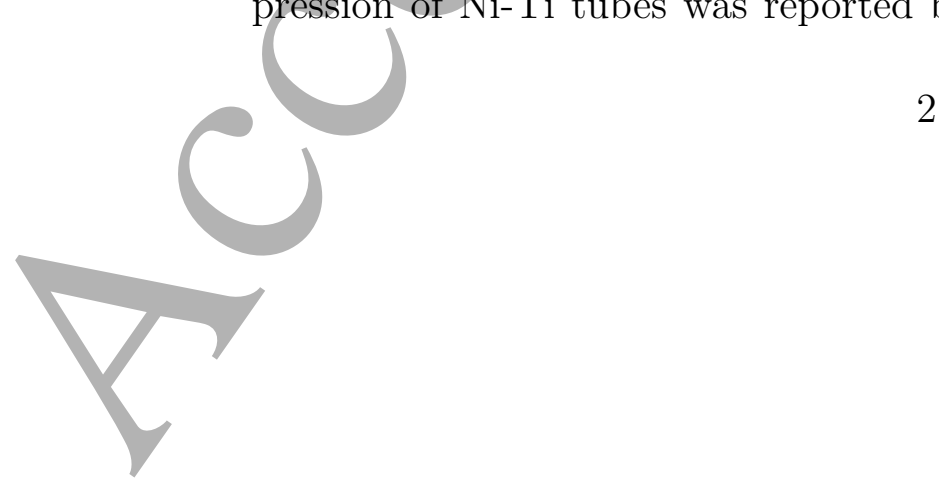


span of $1.5 \mathrm{~K}$. A microcooler based on a single sputtered elastocaloric film in tension achieved a temperature span of $4.2 \mathrm{~K}$ for NiTi and $3.5 \mathrm{~K}$ for $\mathrm{Ni}$ Ti-Cu-Co [19]. These systems generally use some type of thermodynamic cycle, with the exception of the device reported in [2], where the entire elastocaloric material undergoes essentially the same cycle. The system used in this article, however, uses a regenerative cycle where a temperature gradient develops along the active material. Active regenerator cycles have long been used in magnetocaloric cooling to accept a cooling load over a temperature span many times higher than the adiabatic temperature change with magnetization of the active material and also allows multiple materials with Curie temperatures tuned to their local operating conditions to be used [4]. A regenerative cycle is proposed for elastocaloric systems for the same reasons: it allows the device to operate at temperature spans higher than the adiabatic temperature change of the material. It also allows multiple materials to be used in a single regenerator, as has been proven to be beneficial for magnetocaloric systems. This paper presents updates to a previously reported system [27], including new results for the previously tested $\mathrm{Ni}$-Ti regenerator. A second Ni-Ti regenerator with thicker plates and an overall larger mass is also presented. The results show how the amount of elastocaloric material, applied strain and fluid flow profile affect system performance. Both regenerators were run until failure, and both failed between 5000 and 6000 cycles.

\section{Background and Experimental setup}

The regenerative elastocaloric setup used for testing in this work has been previously reported[27], with a maximum temperature span of $15.3 \mathrm{~K}$ for an applied strain of $3.4 \%$. The system has been modified to give more flexible control of the fluid flow and to reduce the total mass of fluid by reducing the pipe length between the regenerator and displacers and external heat exchangers. Both regenerators were built from a stack of Ni-Ti plates that were laser welded into a monolithic regenerator. The first regenerator was made of $0.2 \mathrm{~mm}$ plates with a total of 9 plates and a spacing of $0.2 \mathrm{~mm}$, for which experimental results were previously reported[27]. The second was made from 10 plates of $0.35 \mathrm{~mm}$ thickness with a spacing of $0.35 \mathrm{~mm}$.

The active elastocaloric regenerator cycle consists of four steps and is described in more detail in [3]. The system consists of an elastocaloric material in a porous structure in thermal contact with a hot and cold fluid reservoir.






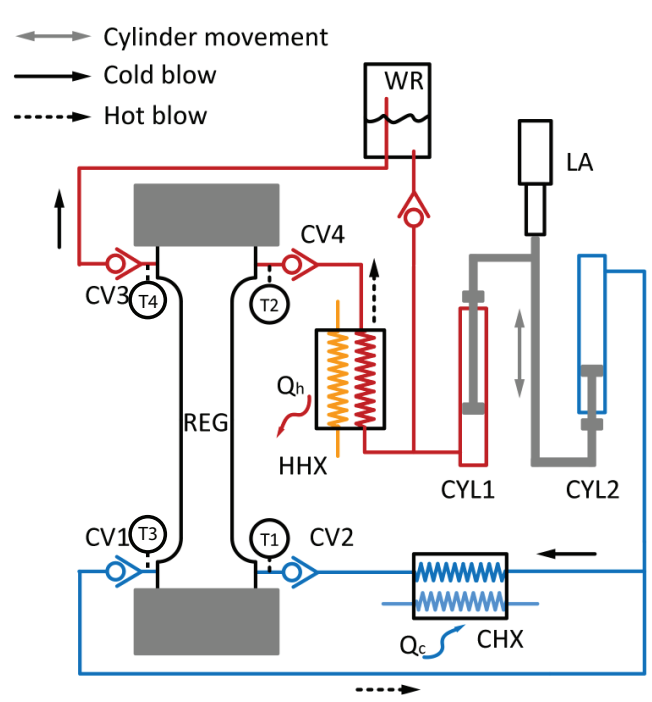

(a)

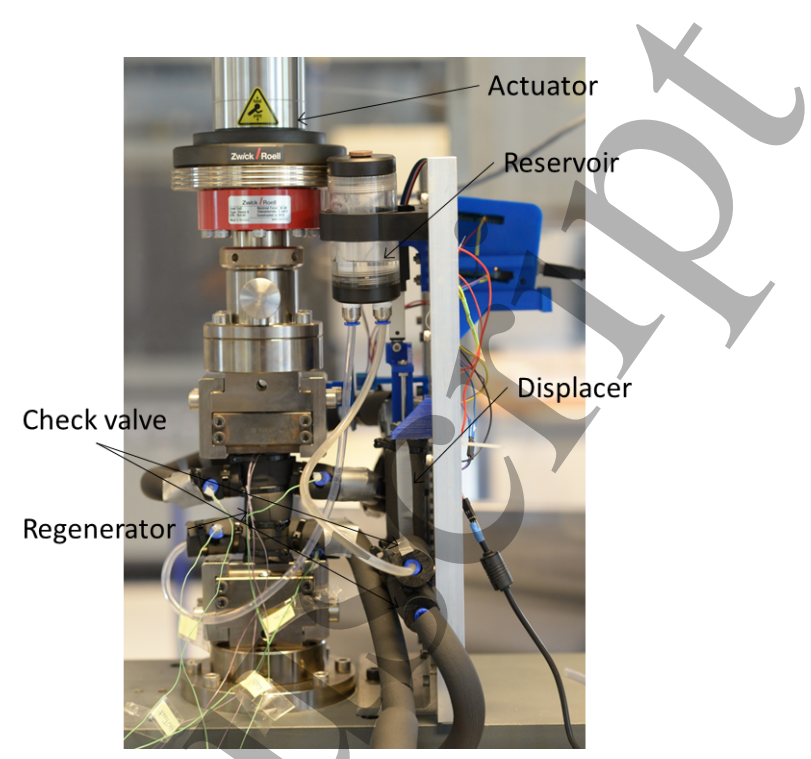

(b)

Figure 1: Illustration of the active elastocaloric regenerator cycle (a) and a photo of the experimental setup (b). $W R$ is the hot reservoir, $C V$ is a check valve, $L A$ is the linear actuator, $C H X$ is the cold heat exchanger, $H H X$ is the hot heat exchanger, and $C Y L$ is a fluid displacer. The cold reservoir is comprised of the fluid volume entrained in $C H X$ and piping connecting it to the regenerator.

First the material is strained, causing it to increase in temperature. Then while the regenerator remains strained, fluid flows from the cold reservoir to the hot, which results in a heat transfer to the hot reservoir while the elastocaloric material is cooled. The strain is then released, causing the material to reduce in temperature. Finally fluid flows from the hot reservoir to the cold reservoir while the strain remains constant. Because the temperature exiting the regenerator is lower than the cold fluid reservoir temperature, the fluid can cool the desired space or system. The cycle needs not necessarily be broken into four distinct steps. In the results section, the effects of overlapping the fluid flow process with the straining process is studied.

The regenerators are constructed by cutting sheets of Ni-Ti into dog bone shapes with an active width of $10 \mathrm{~mm}$. The strain in the plate was measured by the displacement of the mechanical actuator, and since the applied strains are quite high in these experiments the effective length of active material is difficult to define. Strain is based on the equivalent gauge length of $70 \mathrm{~mm}$ [27]. The regenerator is constructed by stacking the dog bone plates with a 
Table 1: Summary of the thin plate regenerator (REG1) and the thicker plate regenerator (REG2).

\begin{tabular}{|ccc|}
\hline Parameter & REG1 & REG2 \\
\hline Material (wt\%) & $\mathrm{Ni}_{55.8} \mathrm{Ti}_{44.2}$ & $\mathrm{Ni}_{56.0} \mathrm{Ti}_{44.0}$ \\
\hline Austentic finish temperature & $280 \pm 5 \mathrm{~K}$ & $264 \pm 5 \mathrm{~K}$ \\
\hline Mass of active material & $5.8 \mathrm{~g}$ & $12.8 \mathrm{~g}$ \\
\hline Specific heat $\left(c_{\mathrm{s}}\right)$ & $430 \mathrm{~J} / \mathrm{kg}-\mathrm{K}$ & $430 \mathrm{~J} / \mathrm{kg}-\mathrm{K}$ \\
\hline Plate thickness & $0.2 \mathrm{~mm}$ & $0.35 \mathrm{~mm}$ \\
\hline Porosity & 0.5 & 0.5 \\
\hline Number of plates & 9 & 10 \\
\hline Regenerator length & $50 \mathrm{~mm}$ & $50 \mathrm{~mm}$ \\
\hline Regenerator width & $10 \mathrm{~mm}$ & $10 \mathrm{~mm}$ \\
\hline Heat transfer fluid & water & water \\
\hline
\end{tabular}

spacer the same thickness as the plates between the dog bones at the clamping area. The entire stack is then laser welded into a single structure shown in Fig. 2, as described in [27]. Two regenerators were tested, and they are summarized in Table 1. Both Ni-Ti alloys were supplied by Memry GmbH. The first regenerator (REG1) is constructed from $0.2 \mathrm{~mm}$ plates that have a higher austenitic finish temperature, $A_{\mathrm{f}}$, than the $0.35 \mathrm{~mm}$ plates used in REG2. The higher $A_{\mathrm{f}}$ means that REG1 was operated at higher temperatures in order to ensure that it was always in the austenitic state when no strain was applied. REG2 has a larger active mass of elastocaloric material and requires more force to transform the regenerator. REG1 required approximately $6 \mathrm{kN}$ to transform the material to martensite during training, while REG2 required approximately $12 \mathrm{kN}$. The force required during operation depends on strain rate, temperature and operating conditions. The larger mass of REG2 means there is more elastocaloric effect to cool the fluid in the system and overcome heat leaks to the enyironment. Finally, REG1 has a lower surface area for heat transfer beçause it uses fewer plates than REG2, but since the plates are more closely stacked, the heat transfer between the solid and fluid is higher for REG1. REG1 is expected to perform better as a regenerator, although the lower mass of active material means the expected cooling power would be correspondingly lower.

Before the regenerator is mounted in the system, each regenerator was trained for 300 cycles by slowly applying a strain. Training Ni-Ti alloys has been shown to improve the uniformity of the elastocaloric effect over the 
entire plate, especially at strains below full transformation [22], which is important because all experiments reported here use a partial transformation of the plate. After training, fluid flow ports are attached near the clamping areas, and the regenerator is wrapped with flax fiber impregnated with silicone in order to give a housing that is able to flex in the direction of strain application but can withstand the pressure force during the fluid flow periods. More details about the system design and regenerator preparation are given in [27]. The strain is applied by a Zwick Roell EZ030 mechanical tester that can apply a maximum force of $30 \mathrm{kN}$. Forces were measured with an Xforce $\mathrm{K}$ load cell with a $30 \mathrm{kN}$ capacity. Fluid flow is provided by a linear actuator coupled to two fluid displacers with check valves to control the flow direction through the system, and water is used as the heat transfer fluid. Temperatures are measured using calibrated thermocouples placed directly in the fluid flow at the inlet and outlet of both the cold and hot fluid circuits. The temperature span is defined as the difference between the temperature of the fluid exiting the hot end of the regenerator and the fluid exiting the cold end once steady state operation has been achieved. Thermocouple locations are marked in Fig 1(a) and the temperature span is the difference between $T 4$ and $T 3$ in the schematic. The experimental setup has been modified from that reported in [27] by reducing the diameter of the displacers from $16 \mathrm{~mm}$ to $10 \mathrm{~mm}$ and mounting them to a more rigid coupling. The control of the actuator that drives the displacers was also improved, allowing different cycle timing to be tested. The displacers are controlled by measuring the position of the mechanical tester using a magnetic linear encoder and commanding the position of the linear actuator attached to the displacers based on the position of the mechanical tester. The displacers and hot heat exchanger were moved closer to the regenerator to reduce the thermal mass in the tubing connected to the regenerator. Efforts were made to thermally insulate all components that are in contact with the fluid. The reduced displacer volume, shorter piping and improved insulation should reduce the time taken to reach steady state, reduce heat leakage and increase the temperature span.

The best operating strategy for an elastocaloric cooler is not clear. The effect of strain and strain rate on the efficiency of a non-regenerative elastocaloric cycle was performed by [28], but a full study on a regenerative elastocaloric cycle has not been performed. The regenerative cycle adds several degrees of freedom not available to non-regenerative cycles, which are employed in most other devices, such as the fluid flow volume, fluid flow rate and timing of the fluid flow process relative to the strain. To study how fluid

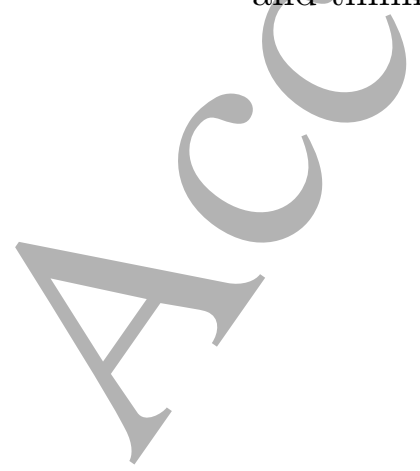




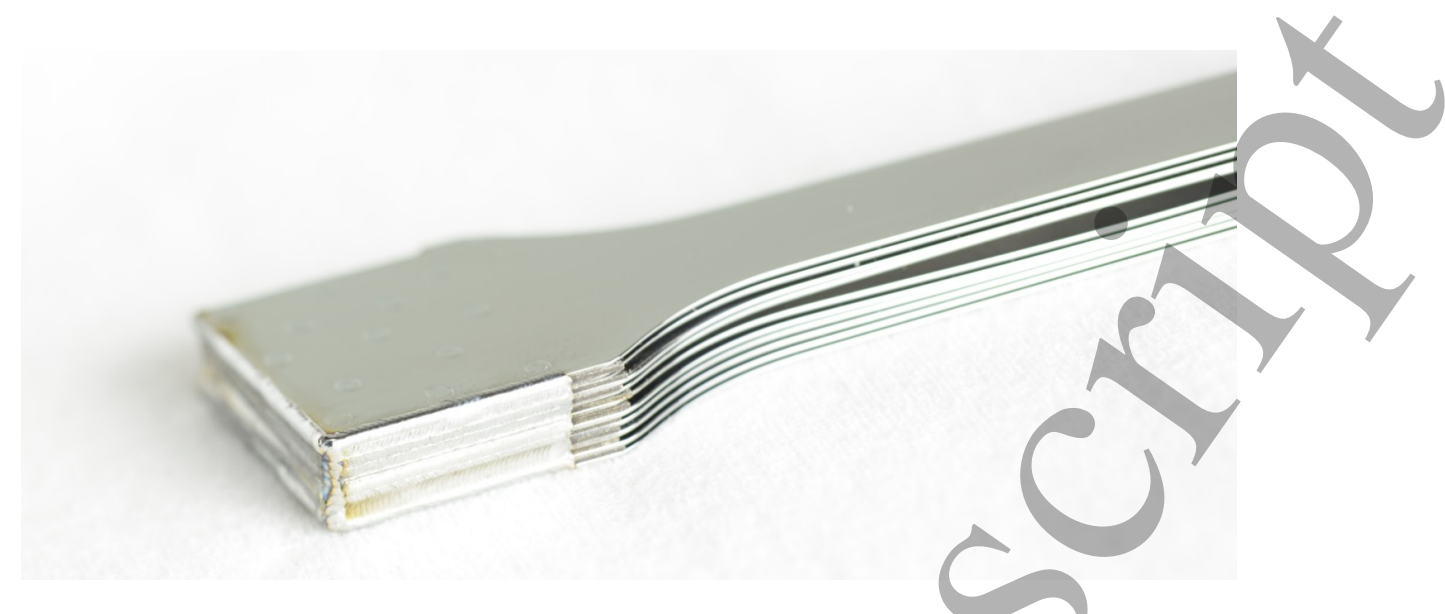

Figure 2: Photograph of the thick plate regenerator (REG2) before it is installed in the test setup. It can be seen that the 4th and 5th plates from the top are deformed from the training process. Other plates are also slightly deformed.

flow timing influences system performance, the normalized strain at which the fluid flow process begins, $\varepsilon_{\text {flow }}$, is introduced.

$$
\varepsilon_{\text {flow }}=\frac{\varepsilon_{\text {flow }, \text { start }}}{\varepsilon_{\text {max }}}
$$

where $\varepsilon_{\text {flow,start }}$ is the change in strain when the fluid flow process starts. During the strain process, this is simply the applied strain, but during the strain release process, it is the difference between the maximum strain and the current strain. $\varepsilon_{\max }$ is the maximum applied strain. $\varepsilon_{\text {flow }}$ varies from 0 to 1 , where 1 indicates that the strain process is fully complete when the fluid flow starts. Starting the fluid flow process before the regenerator is fully strained allows the total cycle time to be reduced while maintaining the same fluid flow period. Higher cycle frequency increases the amount of cooling power a given mass of elastocaloric material can absorb and can make the system more compact. The applied strain, strain rate and hold time once the applied strain has been achieved are all controlled by the software for the mechanical tester. The beginning of the fluid flow process was controlled by using the linear encoder to measure the strain on the regenerator. The strain at which the fluid displacers started moving was controlled by the signal from the linear encoder. An example of the strain and fluid flow profiles for a cycle is shown in Fig. 3.

Due to the failure of REG1, flow timing studies were only performed on REG2. It should be noted that the number of cycles before failure is difficult 


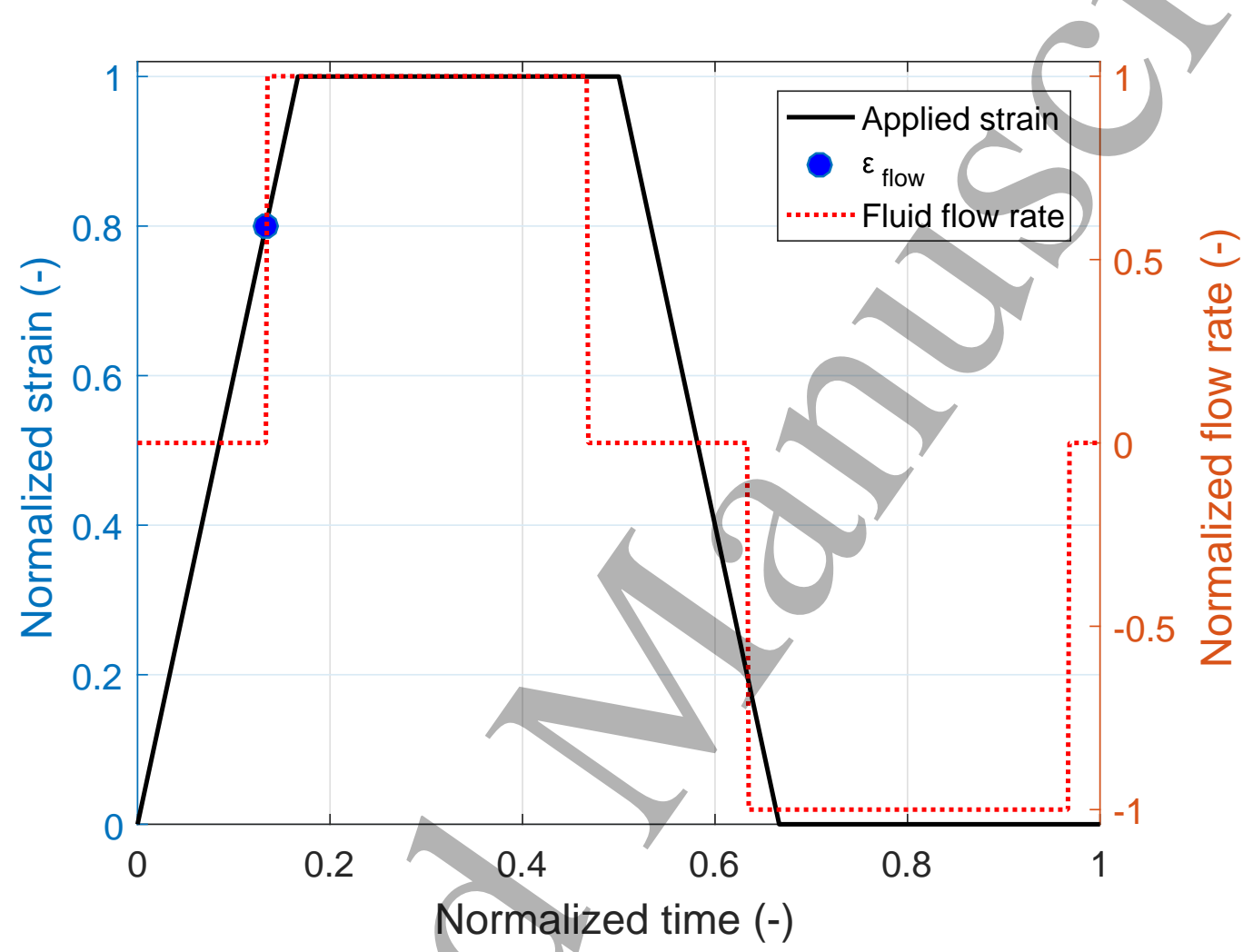

Figure 3: Applied strain and fluid flow rate for an example cycle with a six second period. The positive fluid flow direction is from the cold reservoir to the hot and $\varepsilon_{\text {flow }}$ is labelled. 
to determine for these experiments because many different test actuations of the regenerator were performed in the process of verifying the setup and testing. These test actuations were generally performed without fluid flow so the forces were slightly different than during regenerative cycles. The cycles were also performed over a range of applied strains and strain rates. At steady state, the plate has a temperature gradient in the direction of strain so the cyclical loading of the regenerators in this article are not directly comparable to plates loaded at well controlled constant conditions as usually performed during fatigue testing of shape memory alloy [22].

The fluid flow for regenerators is generally expressed in terms of the utilization, $U$, as defined in Eq. 2. It represents the ratio of the thermal energy entering the regenerator due to fluid flow compared to the total thermal energy entrained in the regenerator.

$$
U=\frac{m_{\text {flow }} c_{\mathrm{f}}}{m_{\mathrm{s}} c_{\mathrm{s}}+m_{\mathrm{f}} c_{\mathrm{f}}}
$$

where $m_{\text {flow }}$ is the mass of fluid that flows into the regenerator during one flow period while $m_{\mathrm{f}}$ is the static mass of fluid entrained in the regenerator, $c_{\mathrm{S}}$ is the specific heat at no strain in the solid $(\mathrm{Ni}-\mathrm{Ti}), c_{\mathrm{f}}$ is the specific heat of the fluid, $m_{\mathrm{s}}$ is the mass of the solid. The values of $m_{\mathrm{s}}$ and $c_{\mathrm{s}}$ used are listed in Table 1 , and the value of $c_{\mathrm{s}}$ corresponds to the baseline specific heat away from the transition temperature [29]. The value of $m_{\text {flow }}$ varies with the displacer stroke. The specific heat of water is assumed to be $4200 \mathrm{~J} / \mathrm{kg}-\mathrm{K}$ based on standard properties.

\section{Results and Discussion}

\subsection{Results for REG1}

First, REG1 was tested under similar conditions to those from [27] to test how the modifications to the test setup affect performance. Before installing the regenerator in the experimental setup, it was trained for 200 cycles at a strain rate of $0.000143 \mathrm{~s}^{-1}$ up to a strain of $4 \%$, as detailed in [27]. The optimal fluid flow displacement was determined for a strain of $1.7 \%$ and a piston stroke of $15 \mathrm{~mm}$, corresponding to a $1.2 \mathrm{~mL}$ fluid displacement $\left(m_{\text {flow }}\right.$ of $1.2 \mathrm{~g}$ ), was shown to give the highest temperature span. The same procedure was performed for this system previously with the $16 \mathrm{~mm}$ displacers. To compare the new setup with the previous, the experiment with an applied strain of $2.9 \%$ and a cycle time of $4 \mathrm{~s}$ was repeated with the updated 
setup and a temperature span of $14.9 \mathrm{~K}$ was achieved. This compares to an approximately $13 \mathrm{~K}$ span previously reported, which indicates that the new setup increases the temperature span of the regenerator by approximately 2 K. Further improvement of the insulation, especially from the regenerator to the mechanical grips could give further improvement to the temperature span. The effect of varying the cycle timing was tested by varying the pause time of the mechanical actuator at the maximum and minimum strain (the time where fluid flow occurs), and therefore varying the total cycle time. Each cycle consists of a $1 \mathrm{~s}$ strain application, a pause, a $1 \mathrm{~s}$ strain release, and a second pause. The pause time varies from $2 \mathrm{~s}$ for the $6 \mathrm{~s}$ cycle to $0 \mathrm{~s}$ for the $2 \mathrm{~s}$ cycle (where there is full overlap in the strain and flow processes). The effect of varying the cycle time is shown in in Fig. 4. The results show that a short pause for the fluid flow improves performance, but additional hold time reduces the temperature span, as the $4 \mathrm{~s}$ and $6 \mathrm{~s}$ cycles had lower temperature spans. The highest temperature span of $15.6 \mathrm{~K}$ was measured for a 3 s cycle.

REG1 was then tested at higher strains than previously reported, up to $4.3 \%$ at the optimized cycle time of $3 \mathrm{~s}$. The increased strain and constant cycle time mean that the strain rate was higher for higher applied strains. The value of $m_{\text {flow }}$ was $1.2 \mathrm{~g}(U=0.85)$ and the flow period was $1 \mathrm{~s}$. However, during testing at $3.7 \%$, two plates failed, as could be determined by the force required to transform the material. Testing of REG1 was continued with only 7 active plates until an additional plate failed at a strain of 4.3 $\%$, and experiments were stopped on REG1. The results obtained before the regenerator failed are shown in Fig. 5. A maximum temperature span of 17.6 K was achieved for REG1. The regenerator failed after an estimated 5200 cycles. As the number of cycles to failure for the entire stack was similar to single plates reported by [22], the failure can likely be attributed to typical fatigue experienced in Ni-Ti plates. After testing was completed the regenerator was inspected and four failed plates were observed. It is impossible to dêtermine which plate failed first. Both outer plates of the stack failed, indicating that the plates that are in direct contact with the clamps may carry more of the mechanical load than the interior ones. The plates all broke somewhere in the middle of the active area, and there is no clear connection between the failure locations and their proximity to the hot or cold reservoirs. Although the temperature span with 7 plates were better than those with 9 plates, the increase is most likely due to the increased strain and does not indicate that the regenerator performed better after two 


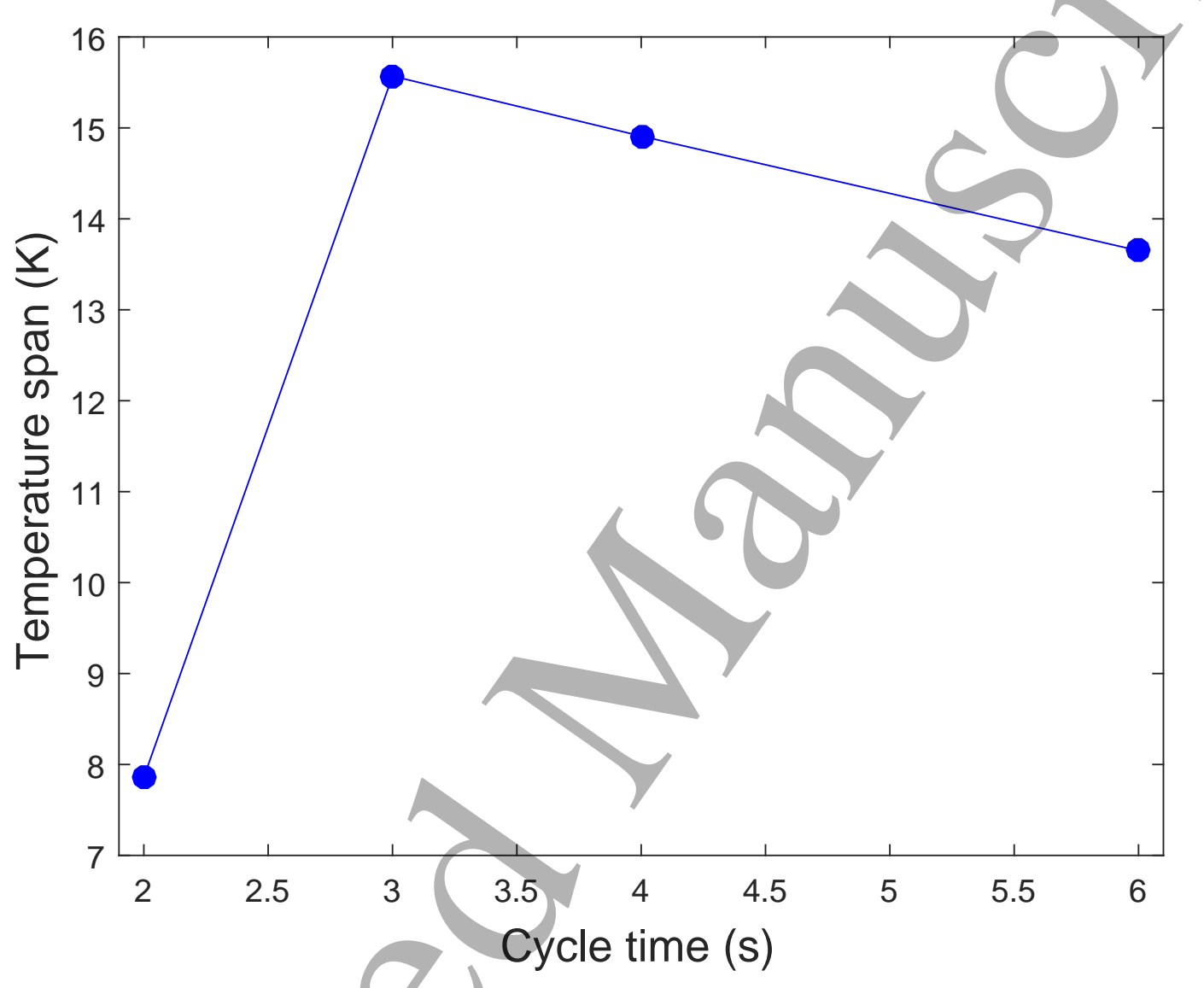

Figure 4: No-load temperature span as a function of cycle time for REG1. 


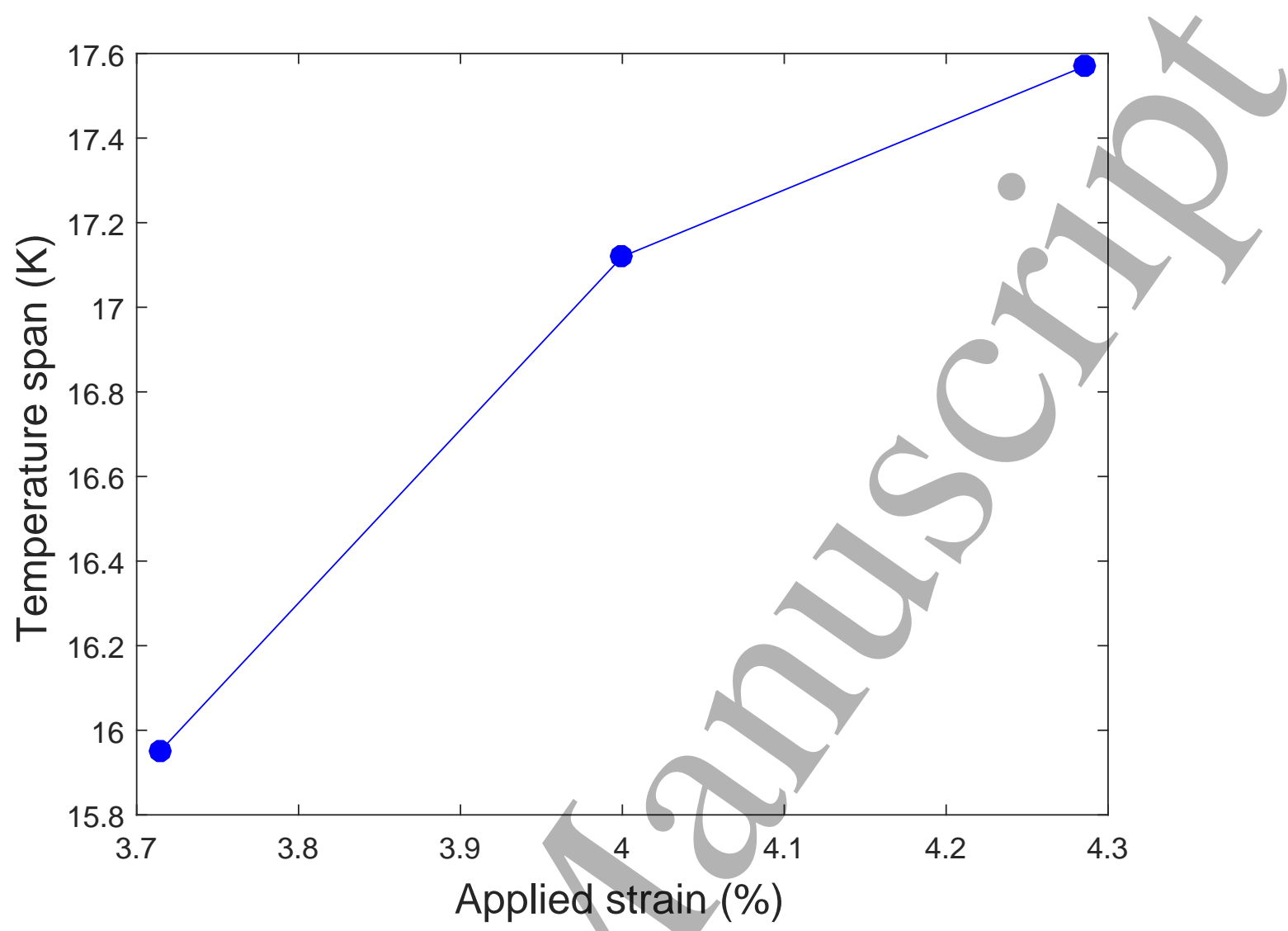

Figure 5: Temperature span as a function of stain for REG1. Cycle time is $3 \mathrm{~s}$ and $U$ is 0.85 .

plates failed.

\subsection{Results for REG2}

REG2 was tested in a similar manner to REG1. Before installing the stack into the device, it was trained for 300 cycles by slowly applying a strain of $3.6 \%$ at a temperature of $303 \mathrm{~K}$. The training process deformed several of the plates as shown in Fig. 2, and a $3 \mathrm{kN}$ force was required to pull all plates parallel to each other. Therefore all experiments start from a base force of $3 \mathrm{kN}$, which is considered 0 strain. The effects of fluid flow and other parameters were tested at lower strains because the regenerator is expected to be able to withstand more cycles, allowing for more investigations. The strain was held constant at $2 \%$, the hot reservoir temperature was set to 298 $\mathrm{K}$, and the utilization was fixed at 0.41 . The cycle timing for all experiments 
Table 2: Cycle timing for all experiments on REG2.

\begin{tabular}{|ccc|}
\hline Cycle time (s) & Strain/release (s) & Hold time (s) \\
\hline 3 & 1 & 0.5 \\
\hline 4 & 1 & 1 \\
\hline 6 & 2 & 1 \\
\hline
\end{tabular}

performed on REG2 is given in Table 2. First, the effects of varying $\varepsilon_{\text {flow }}$ for three cycle times was tested, and the results are shown in Fig. 6. For each cycle time the temperature span was improved by starting the fluid flow before the strain/release process was complete, which means that there is fluid flow during part of the strain application and release. The $4 \mathrm{~s}$ cycle produced slightly higher temperature spans at higher values of $\varepsilon_{\text {flow }}$, but the highest temperature spans were reached by the $3 \mathrm{~s}$ cycle. Results suggest that the shorter the cycle time, the earlier the piston should start in the cycle. For the 3 s cycle, starting the fluid flow early in the cycle can add over $3 \mathrm{~K}$ to the temperature span. Based on the results shown in Fig. 6, a value of 0.6 for $\varepsilon_{\text {flow }}$ was used for all following experiments.

The dependence of temperature'span on the fluid displacement and cycle time are shown in Fig. 7. As was observed for REG1, the 3 s cycle gave the highest temperature span for most displacements. The best $m_{\text {flow }}$ was still $1.2 \mathrm{~g}$, although it corresponds to a lower $U$ for REG2 because the mass of Ni-Ti is higher. The higher displacements were not possible with the $3 \mathrm{~s}$ cycle because the piston actuator could not move fast enough to complete the stroke in the available time.

After the operating conditions were determined, the regenerator was tested at higher applied strains. The cycle time was fixed at $3 \mathrm{~s}$, meaning that the strain rate varies with applied strain. $U$ was 0.41 and $\varepsilon_{\text {flow }}$ was 0.6. For strains above $3 \%$, the cycle time was longer than $3 \mathrm{~s}$ because the grips of the mechanical actuator slipped at the higher strain rates. In these cases, the minimum possible cycle time was used. Although it was shown that operating at lower values of $U$ gives higher temperature spans, they also result in experiments that take longer to reach steady state and require more cycles on the regenerator. Due to the concern of regenerator failure, a higher $U$ value was chosen to allow for more experiments to be run for a given number of cycles on the regenerator. It would be expected that higher temperature spans could be achieved by using a lower $U$, although the regenerator may have failed before the same number of experiments had been 


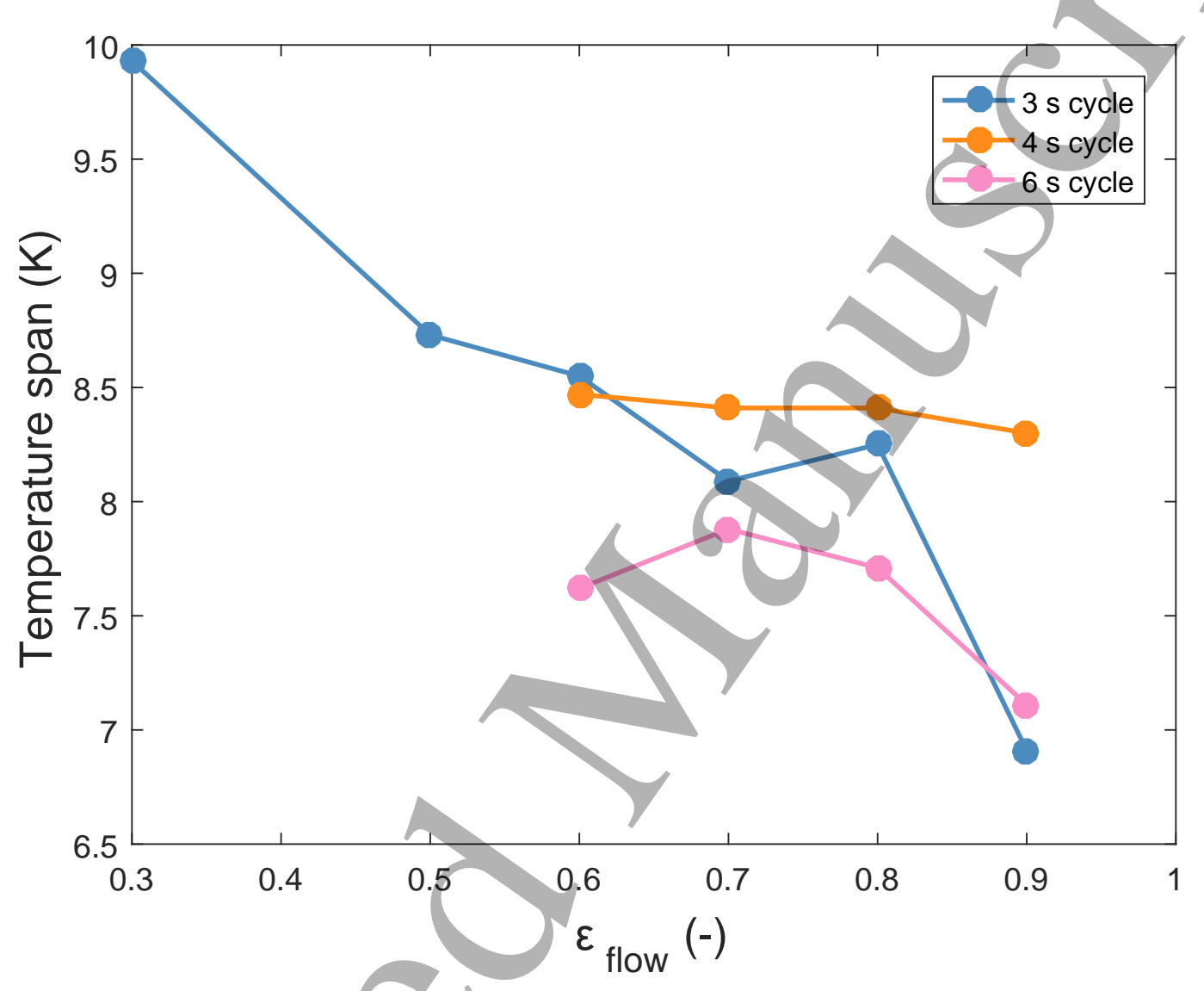

Figure 6: No-load temperature span for REG2 as a function of change in strain when the fluid flow process starts at a utilization of 0.41 . 


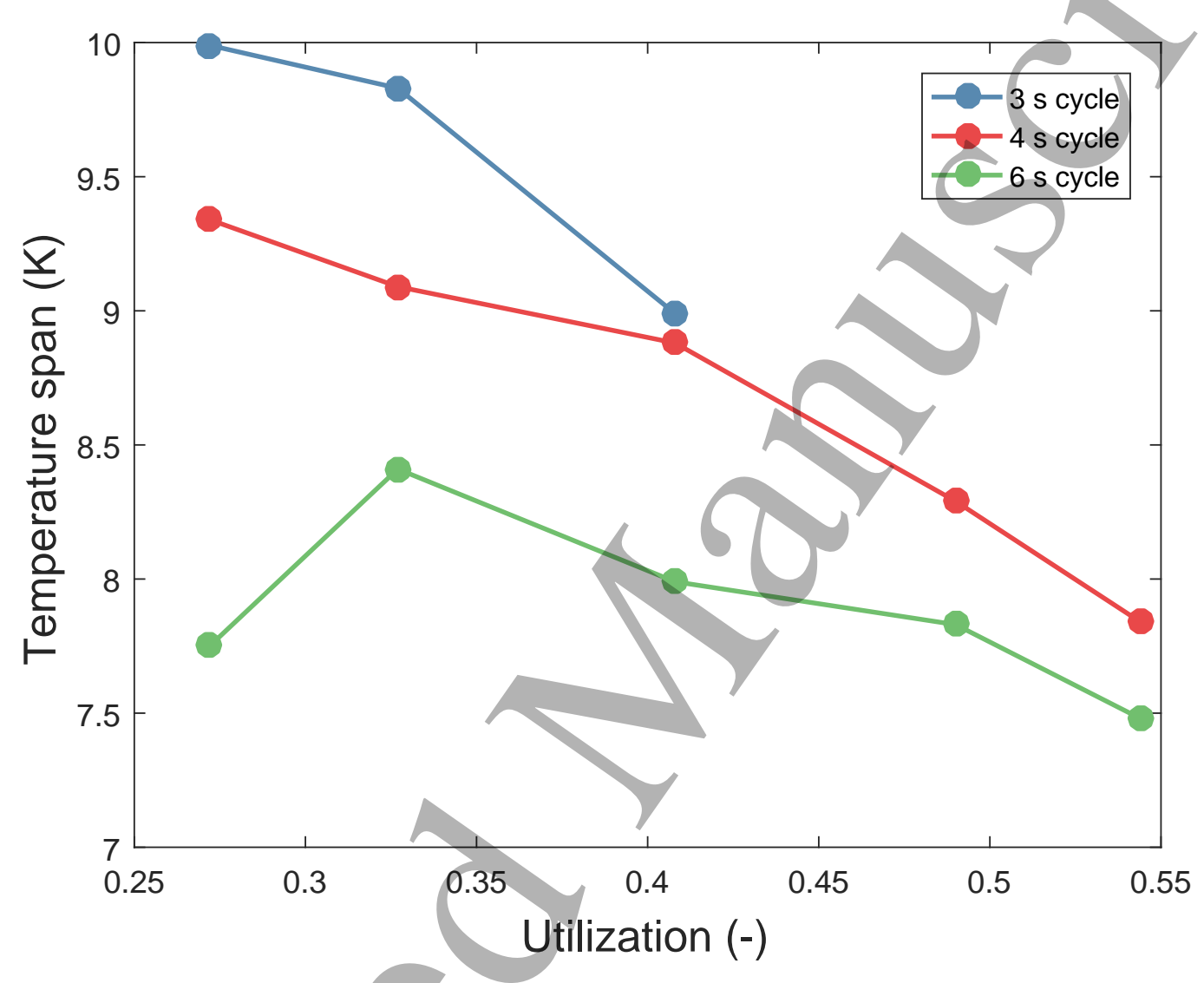

Figure 7: No-load temperature span for REG2 as a function of fluid displacement and cycle time for $\varepsilon_{\text {flow }}=0.6$. 
completed. The results for the high strain experiments are shown in Fig. 8 for the hot reservoir temperature held at $298 \mathrm{~K}$. High strain results for REG1 are also plotted for reference, but it should be noted that REG1 operated with two broken plates for the high strain results. The temperature span increased from $18.9 \mathrm{~K}$ to $19.5 \mathrm{~K}$ by increasing the hot reservoir temperature to $308 \mathrm{~K}$ and applying a strain of $3.5 \%$, and a maximum temperature span of $19.9 \mathrm{~K}$ was measured for a hot reservoir temperature of $310 \mathrm{~K}$. During the $3.5 \%$ strain test at a hot reservoir temperature of $310 \mathrm{~K}$, a plate in the regenerator failed and the experiments were shut down. Upon disassembly of the system, it was observed that one of the interior plates failed in an area near the middle of the plate. The regenerator failed after approximately 5500 cycles. Fatigue testing was done on the same plates that REG1 was fabricated from using the same polishing technique, and the results were reported in [22]. Fatigue testing of the individual plate gave a similar result as the stack of 10 plates, which indicates that testing of individual plates may give a good representation of fatigue life of a regenerator. The fatigue lives of the regenerators tested here were far too low for practical applications and methods to improve fatigue life of elastocaloric regenerators are needed.

REG2 was able to produce a higher no-load temperature span than REG1; however, it is difficult to know the reason for this. REG1 was tested extensively on the previous setup, which was shown to produce lower temperature spans. The highest temperature spans achieved by REG1 were after several of the plates had failed, so it is possible that REG1 could have given better results than REG2 if it had not failed.

Finally, it was shown that temperature spans measured for this device are higher than adiabatic temperature changes measured on the Ni-Ti material used as a refrigerant [30]. This indicated that a regenerative elastocaloric device can operate at a temperature span higher than the adiabatic temperature change of the refrigerant, as has also been shown for magnetocaloric devices. This is an important result, as it shows that the temperature span of an elastocaloric cooler or heat pump is not limited by the adiabatic temperature of its refrigerant.

\section{Conclusions}

Experimental results for two flat plate elastocaloric regenerators made of different $\mathrm{Ni}$ - $\mathrm{Ti}$ plates were presented. It was shown that by reducing the volume of liquid entrained in the system and reducing piping length,

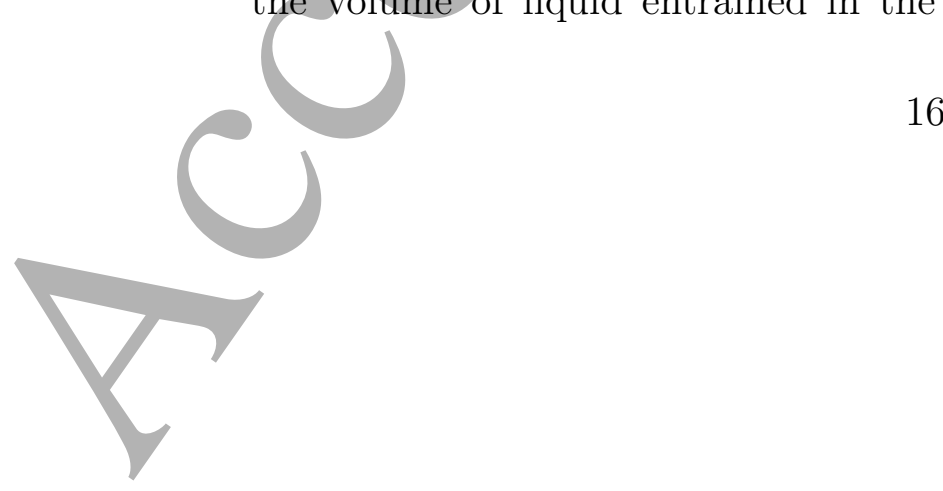




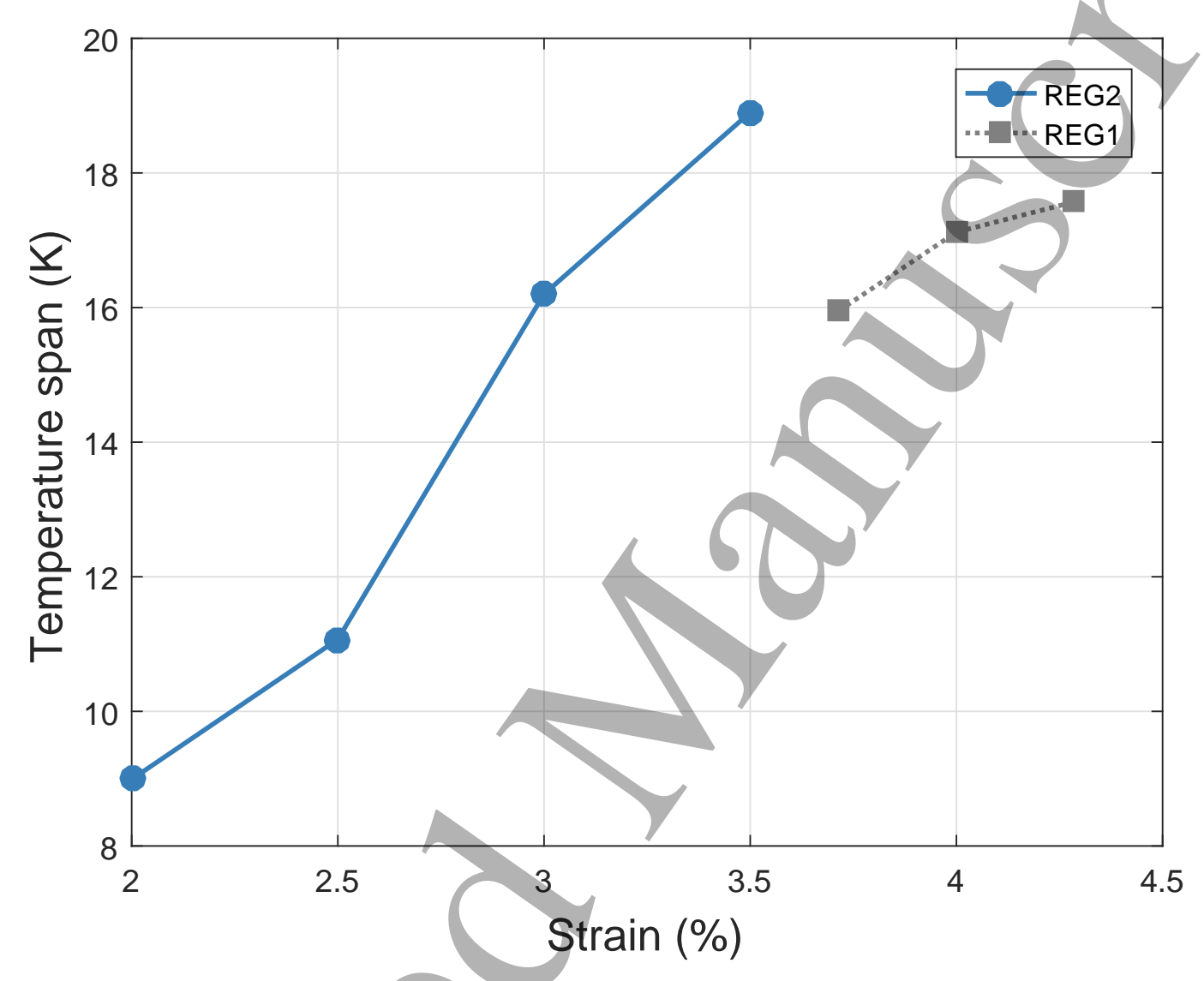

Figure 8: Temperature span as a function of strain for REG2 at higher strains with a hot reservoir temperature of $298 \mathrm{~K}, U$ of 0.41 , and $\varepsilon_{\text {flow }}$ of 0.6 as well as the results plotted in Fig. 5 for REG1. 
the temperature span improved by approximately $2 \mathrm{~K}$ for a given strain. Additionally, starting the fluid flow during the straining process was shown to further increase the temperature span by $3 \mathrm{~K}$ for a $2 \%$ strain while all other parameters were held constant. The regenerator made from $0.2 \mathrm{~mm}$ plates (REG1) achieved a maximum temperature span of $17.6 \mathrm{~K}$ compared to $15.3 \mathrm{~K}$ from previously reported experiments. The regenerator with $0.35 \mathrm{~mm}$ plates was shown to achieve a temperature span of $19.9 \mathrm{~K}$ at an applied/strain of 3.5 $\%$, which is the highest temperature span that this system has achieved to date and the highest reported for an elastocaloric system. The temperature span the device could achieve was shown to be a direct function of the applied strain. Although neither regenerator was tested up to full transformation, indicating that improved performance is possible, testing of both regenerators was limited by the fatigue life of the $\mathrm{Ni}-\mathrm{Ti}$ plates. Both regenerators failed before 6000 cycles, highlighting the need to improve fatigue life of such a system.

\section{Acknowledgements}

Jaka Tušek would like to acknowledge Slovenian Research Agency (Project No. Z2-7219) for supporting this work. Chong-Yi Lee acknowledges support from a Region of Rhône-Alpes - Explo'ra Sup Grant for Student Mobility.

[1] S. Fähler, U. K. Rößler, O. Kastner, J. Eckert, G. Eggeler, H. Emmerich, P. Entel, S. Müller, E. Quandt, and K. Albe. Caloric effects in ferroic materials: New concepts for cooling. Adv. Energy Mater., 14:10-19, 2012 .

[2] S. Qian, D. Nasuta, A. Rhoads, Y. Wang, Y. Geng, Y. Hwang, R. Radermacher, and I. Takeuchi. Not-in-kind cooling technologies: a quantitative comparison of refrigerants and system performance. Int. J. Refrigeration, 62:177-192, 2016.

[3] J Tušek, K. Engelbrecht, R. Millán-Solsona, L. Ma nosa, E. Vives, L. P. Mikkelsen, and N. Pryds. The elastocaloric effect: A way to cool efficiently. Adv. Energy Mater., 5:1500361, 2015.

[4] A. Kitanovski, U. Plaznik, U. Tomc, and A. Poredoš. Present and future caloric refrigeration and heat-pump technologies. Int. J. Refrigeration, 57:288-298, 2015. 
[5] W. Goetzler, R. Zogg, J. Young, and C. Johnson. Energy savings potential and rd\&d opportunities for non-vapor-compression hvac technologies. Technical report, Navigant Consulting, Inc., prepared for U.S. Department of Energy, 2014.

[6] L. Manosa and A. Planes. Materials with giant mechanocaloric effects: Cooling by strength. Advanced Materials, 29(11):1603607, 2017.

[7] H. Ossmer and M. Kohl. Elastocaloric cooling: Stretch to actively cool. Nature Energy, 2016.

[8] J. Cui, Y. Wu, J. Muehlbauer, Y. Hwang, R. Radermacher, S. Fackle, M. Wuttig, and I. Takeuchi. Demonstration of high efficiency elastocaloric cooling with large $\Delta \mathrm{t}$ using niti wires. Appl. Phys. Lett., 101:073904, 2012.

[9] H. Ossmer, F. Lambrecht, M. Gültig, C. Chluba, E. Quandt, and M. Kohl. Evolution of temperature profiles in tini films for elastocaloric cooling. Acta Materialia, 81:9-20, 2014.

[10] J Tušek, K. Engelbrecht, L. P. Mikkelsen, and N. Pryds. Elastocaloric effect of the ni-ti wire for application in a cooling device. J. Appl. Phys., 117:124901, 2015.

[11] M. Schmidt, J. Ullrich, A. Wieczorek, J. Frenzel, A. Schütze, G. Eggeler, and S. Seelecke. Thermal stabilization of niticuv shape memory alloys: Observations during elastocaloric training. Shap. Mem. Superelasticity, 1:132-141, 2015.

[12] L. Manosa, S. Jarque-Farnos, E. Vives, and A. Planes. Large temperature span and giant refrigerant capacity in elastocaloric cu-zn-al shape memory alloys. Appl. Phys. Lett., 103:211904, 2013.

[13] F. Xiao, T. Fukuda, T. Kakeshita, and X. Jin. Elastocaloric effect by a weak first-order transformation associated with lattice softening in an fe-31.2pd (at.\%) alloy. Acta Mater., 87:8-14, 2015.

[14] S. Patel, A. Chauhan, R. Vaish, and P. Thomas. Elastocaloric and barocalôric effects in polyvinylidene di-fluoride-based polymers. Applied Physical Letters, 108(7):072903, 2016. 
[15] Z. Xie, G. Sebald, and D. Guyomar. Elastocaloric effect dependence on pre-elongation in natural rubber. Appl. Phys. Lett., 107:081905, 2015.

[16] Z. Xie, G. Sebald, and D. Guyomar. Comparison of direct and indirect measurement of the elastocaloric effect in natural rubber. Applied Physical Letters, 108(4):041901, 2016.

[17] W. Sun, J. Liu, B. Lu, Y. Li, and A. Yan. Large elastocaloric effect at small transformation strain in $\mathrm{ni}_{45} \mathrm{mn}_{44} \mathrm{Sn}_{11}$ metamagnetic shape memory alloys. Scripta Materialia, 114:1-4, 2016.

[18] Y. Liu, I. C. Infante, X. Lou, L. Bellaiche, J. F. Scott, and B. Dkhil. Giant room-temperature elastocaloric effect in ferroelectric ultrathin films. Advanced Materials, 26(35):6132-6137, 2014.

[19] H. Ossmer, C. Chluba, M. Gueltig, E. Quandt, and M. Kohl. Tini-based films for elastocaloric microcoolingfatigue life and device performance. APL Materials, 4:064102, 2016.

[20] J. Otubo, O. D. Rigo, A. A. Coelho, C. M. Neto, and P. R. Mei. The influence of carbon and oxygen content on the martensitic transformation temperatures and enthalpies of niti shape memory alloy. Materials Science and Engineering A, 481-482:639 642, 2008.

[21] J. Frenzel, A. Wieczorek, I. Opahle, B. Maa, R. Drautz, and G. Eggeler. On the effect of alloy composition on martensite start temperatures and latent heats in niti-based shape memory alloys. Acta Materialia, 90:213$231,2015$.

[22] K. Engelbrecht, J Tušek, S. Sanna, D. Eriksen, O. V. Mishin, and N. Pryds. Effects of surface finish and mechanical training on ni-ti sheets for elastocaloric cooling. APL Materials, 4(6):064110, 2016.

[23] C. Chluba, W. Ge, R. Lima de Miranda, J. Strobel, L. Kienle, E. Quandt, and M. Wuttig. Ultralow-fatigue shape memory alloy films. Science, 348:1004-1007, 2015.

[24] H. Ossmer, S. Miyazaki, and M. Kohl. Elastocaloric heat pumping using a shape memory alloy foil device, solid-state sensors, actuators and microsystems. In 18th International Conference on Transducers, pages 726-729, 2015. 
[25] M. Schmidt, A. Schütze, and S. Seelecke. Scientific test setup for investigation of shape memory alloy based elastocaloric cooling processes. Int. J. Refrigeration, 54:88-97, 2015.

[26] H. Ossmer, F. Wendler, M. Gueltig, F. Lambrecht, S. Miyazaki, and M. Kohl. Energy-efficient miniature-scale heat pumping based on shape memory alloys. Smart Materials and Structures, 2016.

[27] J. Tušek, K. Engelbrecht, D. Eriksen, S. Dall'Olio, J. Tušek, and N. Pryds. A regenerative elastocaloric heat pump. Nature Energy, $1: 16134,2016$.

[28] M. Schmidt, S.-M. Kirsch, S. Seelecke, and A. Schütze. Elastocaloric cooling: From fundamental thermodynamics to solid state air conditioning. Science and Technology for the Built Environment, 22(5):475-488, 2016.

[29] J Tušek, K. Engelbrecht, L. Ma nosa, E. Vives, and N. Pryds. Understanding the thermodynamic properties of the elastocaloric effect through experimentation and/modelling. Shap. Mem. Superelasticity, 2(4):317-329, 2016.

[30] J. Tušek, K. Engelbrecht, and N. Pryds. Elastocaloric effect of a Ni-Ti plate to be applied in a regenerator-based cooling device. Science and Technology for the Built Environment, 22(5):489-499, 2016. 